\title{
Influence of water conductivity on micro-discharges from raindrops in strong electric fields
}

\author{
M.P. Boussaton*, S. Coquillat, S. Chauzy, J.F. Georgis \\ Laboratoire d'Aérologie, UMR UPS/CNRS No. 5560, Observatoire Midi-Pyrénées, Toulouse, France
}

The influence of water conductivity on micro-discharges from raindrops has been studied by submitting water drops of different conductivities, falling at terminal velocity, to strong horizontal electric fields. The discharge onset field remains quite unchanged but the micro-discharges characteristics are clearly affected by the nature of water - scarce high amplitude pulses for low water conductivity and numerous low amplitude pulses for higher water conductivity. The influence of water conductivity on the onset streamer pulse mode of discharge is analysed. It is thought that the negative charge at the head of the positive avalanche is faster absorbed by the drop surface with rainwater, thus the reactivation of the pulses is faster. Possible implications of such behaviour are discussed in the light of recent studies on the influence of pollution on lightning activity.

Keywords: Lightning; Atmospheric pollution; Microphysics; Micro-discharge; Water conductivity

\section{Introduction}

Studying micro-discharges from raindrops is of interest because corona discharges from hydrometeors are supposed to be the first stage of lightning initiation. Electrical corona (also called point discharge) has been treated by many authors. Loeb (1965), in

\footnotetext{
* Corresponding author.

E-mail address: boum@aero.obs-mip.fr (M.P. Boussaton).
} 
particular, has broadly investigated the problem of corona discharge mechanism. He showed that point discharge is initiated near the point by the acceleration of free electrons provided the electric field is strong enough. These electrons then ionise gas molecules and create an electron avalanche. The discharge starts with short duration pulses called burst pulses or onset streamers and can develop into a steady signal while the electric field increases. Whereas Loeb principally considered discharges from metal points, numerous studies have been conducted on corona emission from hydrometeors (English, 1948; Dawson, 1969; Griffiths and Latham, 1972, 1974). One of the latest, carried out by Schroeder et al. (1999), presents a detailed numerical analysis of the phenomenon and shows that positive corona can occur at observed in-cloud electric fields when two drops undergoing collision produce a long liquid filament that highly enhances the local electric field according to Crabb and Latham (1974). However, until now, no experiment has documented the bipolar discharge from raindrops falling at terminal velocity.

Several parameters that govern micro-discharges from raindrops have been largely explored; particularly pressure, and water drop size and charge (Dawson, 1969; Griffiths and Latham, 1972; Georgis et al., 1995). Among these parameters, water conductivity has been seldom considered though its influence has been pointed out for the flashover of water drops on hydrophobic insulator surfaces (Windmar, 1994). Moreover, Griffiths and Latham (1974) noticed an effect of conductivity on ice particles. They showed that there is a critical temperature from which ice conductivity is too weak to allow micro-discharges from ice hydrometeors. Contaminating ice particles with ammonia, which means increasing ice conductivity, leads to decrease this critical temperature below which corona emission is inhibited.

Several recent studies tend to suspect an influence of atmospheric contaminants on lightning. They show a modification of lightning activity over cities (Westcott, 1995; Soriano and de Pablo, 2002; Steiger et al., 2002) or during a fire of biomass event (Lyons et al., 1998; Murray et al., 2000). This modification could originate from several parameters like urban heat island, cloud condensation nuclei (CCN) concentration, but also from moisture according to Smith et al. (2003). Water conductivity that is much affected by pollutants could also play a part.

A laboratory experiment has been performed so as to observe the impact of water conductivity on micro-discharges from raindrops. Using different types of water, we submitted falling drops to strong electric fields. The signals produced by the drops were measured and the different electrical behaviours were analysed. In a second step, laboratory results are attempted to be linked with large-scale electrical phenomenon in order to draw up conclusions about lightning activity.

\section{Experimental device and procedure}

The experimental device is similar to that used by Georgis et al. (1997) and a change of site allowed us to set up a vertical tunnel $17 \mathrm{~m}$ high which ensures all the drops to reach more than $99 \%$ of their terminal velocity in still air (see Wang and Pruppacher, 1977). In this way, the generated drops falling at atmospheric pressure are fully aerodynamically 
distorted. Furthermore, the oscillations they can undergo at release are sufficiently damped (see Georgis et al., 1997) for ensuring that a drop of given size has approximately the same shape (equilibrium shape in absence of electric field) when entering the electric field. Their time of residence in the horizontal field being about $40 \mathrm{~ms}$, it is long enough for the drops to be electrically distorted and to undergo disruption (see Brazier-Smith and Latham, 1969; Georgis et al., 1997). The horizontal field is created between two polished and chromed copper plates $40 \mathrm{~cm}$ high and $30 \mathrm{~cm}$ wide with rounded edges for avoiding any undesirable current leakage by corona effect. The positions of the drops inside the field are inevitably scattered around the centre of the capacitor after a fall of $17 \mathrm{~m}$ (typically over a distance of $4 \mathrm{~cm}$ ) therefore the plates are separated by a rather large distance of $10 \mathrm{~cm}$. Consequently the applied voltage has to be high enough to ensure high field intensities up to more than $800 \mathrm{kV} / \mathrm{m}$.

Subsequent problems arise from this high voltage configuration: current leakage from circuit connections, unsafe conditions, etc. To minimize them, symmetrical potentials are applied on both plates contrary to previous studies on corona discharge from raindrops or ice crystals (Richards and Dawson, 1971; Griffiths and Latham, 1974; Kamra and Ahire, 1989, Kamra et al., 1993) in which one of the electrodes was connected to the ground. These potentials are applied with high voltage DC supplies of 0 to $\pm 100 \mathrm{kV}$ via resistors $R$ of $100 \mathrm{M} \Omega$ (Fig. 1). The use of such high resistors prevents from shunting any amount of the current discharge into the generators that could lead to an underestimation of the actual current discharge in the measurement circuit.

The apparatus being designed to simultaneously detect the negative and positive currents emitted from both sides of the drop, two capacitors $C=60 \mathrm{nF}$ are used to avoid any direct connection of the 2-input oscilloscope (LeCroy 9370L, $r=50 \Omega$ input impedance, $1 \mathrm{GHz}$ bandwidth) to the high voltage circuit. Most of the measurements are performed with a sample rate of $50 \mathrm{MS} / \mathrm{s}(20 \mathrm{~ns} / \mathrm{pt})$ that ensures a total length of the signal equal to $40 \mathrm{~ms}$ since the memory available is $2 \mathrm{M}$ points. The current intensity $I$ is deduced from the detected voltage $V$ according to $I=2 \mathrm{~V} / \mathrm{r}$. In the present experiment, the maximum electric charge carried by a whole discharge does not exceed $70 \mathrm{nC}$. This

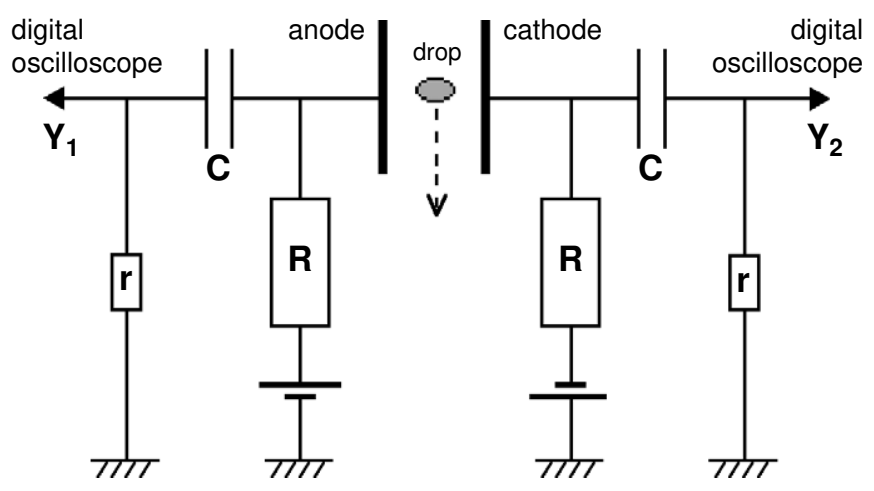

Fig. 1. Electrical circuit. 
is markedly lower than the global charge accumulated in each capacitor $C$, which reaches $1.8 \mathrm{mC}$ for the lowest average voltage of $30 \mathrm{kV}$. Therefore the discharge process does not affect the electric field and no recharging of the capacitors disturbs the current signal.

Two types of water were used: pure water for reference and rainwater collected near the French city of Toulouse. The composition of each type of water is presented in Table 1 . Rainwater contains higher ion concentration (chloride, nitrate, sulphate, sodium, potassium, calcium, magnesium) than pure water. Consequently, the rainwater conductivity $(14.7 \mu \mathrm{S} / \mathrm{cm})$ is higher than that of pure water $(2.6 \mu \mathrm{S} / \mathrm{cm})$. Both are lower than that, ranging between 21.7 and $526 \mu \mathrm{S} / \mathrm{cm}$, used by Windmar (1994). Unfortunately no fruitful comparison can be drawn with his data since he only focused on the flashover of water drops, i.e. in higher electric fields.

The main difference in the chemical composition of the two types of water principally resides in the nitrate and sulphate concentrations, which permits to conclude that the characteristics of the rainwater used in present experiment are much more typical of an anthropogenic pollution. However, these concentrations remain quite low: actually, ions concentration can be much more important in the case of significant oceanic environment (sodium and chloride) or anthropogenic pollution (nitrate and sulphate essentially). Thus, rainwater conductivity can reach higher values. For example, Vázquez et al. (2003) measured in the Illas Cies (Spanish island in the region of Galicia) a mean conductivity of $163.7 \mu \mathrm{S} / \mathrm{cm}$, which is the result of high mean concentrations in sodium (494 $\mu \mathrm{Eq} / \mathrm{l})$ and chloride $(610 \mu \mathrm{Eq} / \mathrm{l})$. Concerning anthropogenic pollution, we can mention the observations of Sanusi et al. (1996) who found a maximum conductivity that reached $325 \mu \mathrm{S} / \mathrm{cm}$ in rainwater collected in the French city of Colmar, with a mean conductivity of $60 \mu \mathrm{S} / \mathrm{cm}$ corresponding to the presence of nitrate $(78 \mu \mathrm{Eq} / \mathrm{l})$ and sulphate $(147 \mu \mathrm{Eq} / 1)$.

In the present experiment, we tried to detect the onset field of corona discharge for uncharged water drops of known sizes - radii equal to $1.93,2.33$, and $2.76 \mathrm{~mm}( \pm 0.1$ $\mathrm{mm})$ - that were produced singly at the top of the vertical tunnel at room temperature $\left(25{ }^{\circ} \mathrm{C}\right)$. For each size, the electric field intensity was increased by a small amount until the occurrence of the disruption, which was characterized by the triggering of the oscilloscope and a specific noise.

Table 1

Ionic components concentrations and conductivity of pure water and rainwater

\begin{tabular}{|c|c|c|c|c|c|}
\hline \multirow[t]{2}{*}{ Properties } & & \multicolumn{2}{|c|}{ Pure water } & \multicolumn{2}{|c|}{ Rain water } \\
\hline & & $\mu \mathrm{Eq} / 1$ & $\mathrm{~mol} / \mathrm{kg}$ & $\mu \mathrm{Eq} / 1$ & $\mathrm{~mol} / \mathrm{kg}$ \\
\hline \multirow[t]{3}{*}{ Anion concentration } & $\mathrm{Cl}^{-}$ & 0.81 & $8.10 \times 10^{-7}$ & 7.18 & $7.18 \times 10^{-6}$ \\
\hline & $\mathrm{NO}_{3}^{-}$ & 0.08 & $8.39 \times 10^{-8}$ & 14.08 & $1.41 \times 10^{-5}$ \\
\hline & $\mathrm{SO}_{4}^{2-}$ & 0.22 & $1.09 \times 10^{-7}$ & 21.9 & $1.09 \times 10^{-5}$ \\
\hline \multirow[t]{4}{*}{ Cation concentration } & $\mathrm{Na}^{+}$ & 3.13 & $3.13 \times 10^{-6}$ & 20.83 & $2.08 \times 10^{-5}$ \\
\hline & $\mathrm{K}^{+}$ & 2.67 & $2.67 \times 10^{-6}$ & 6.4 & $6.40 \times 10^{-6}$ \\
\hline & $\mathrm{Mg}^{2+}$ & 0 & 0 & 8.14 & $4.07 \times 10^{-6}$ \\
\hline & $\mathrm{Ca}^{2+}$ & 12.06 & $6.03 \times 10^{-6}$ & 43.76 & $2.19 \times 10^{-5}$ \\
\hline Conductivity $(\mu \mathrm{S} / \mathrm{cm})$ & & 2.6 & & 14.7 & \\
\hline
\end{tabular}




\section{Results and interpretation}

\subsection{Instability onset field}

The measured instability onset field is displayed in Fig. 2 and compared with previous studies. It decreases from about 800 to $650 \mathrm{kV} / \mathrm{m}$ for equivalent drop radius increasing from 1.93 to $2.76 \mathrm{~mm}$, respectively. It corresponds to the lowest bound of all the data relating to the fall of raindrops in still air (Macky, 1931; Ausman and Brook, 1967; Georgis et al., 1997). The difference actually arises from the height of fall of the raindrops - respectively, $50 \mathrm{~cm}, 2 \mathrm{~m}$, and $14 \mathrm{~m}$ - that did not allow them to fully reach their terminal velocity, which is a key parameter in raindrop distortion in a horizontal electric field (see Coquillat et al., 2003). For example, the increase in the height of the tunnel from $14 \mathrm{~m}$ (Georgis et al., 1997) to $17 \mathrm{~m}$, which allows the drops to reach more than $99 \%$ of their terminal velocity according to Wang and Pruppacher (1977), corresponds to a reduction of about $4 \%$ of the onset field. When considering the data by Kamra et al. (1993), one must keep in mind that the corresponding experiment was realized in a wind tunnel in which the raindrops undergo oscillations and vibrations due to the induced turbulence. Therefore the turbulence affects the behaviour of the raindrops in such a way that the onset field in still air must be regarded as the upper bound of the in-cloud instability onset field.

One can point out that the presently measured electric fields required to produce instability/breakdown range between 650 and $800 \mathrm{kV} / \mathrm{m}$ at the ground for uncharged raindrops. They are therefore somewhat larger than the maximum electric field ever measured inside a thunderstorms (around $400 \mathrm{kV} / \mathrm{m}$, see MacGorman and Rust, 1998). Moreover, these onset fields are not expected to be significantly reduced aloft since, on one hand the water drop distortion due to the increasing fall velocity in decreasing pressure is counterbalanced by the increase in surface tension with decreasing temperature, and in the

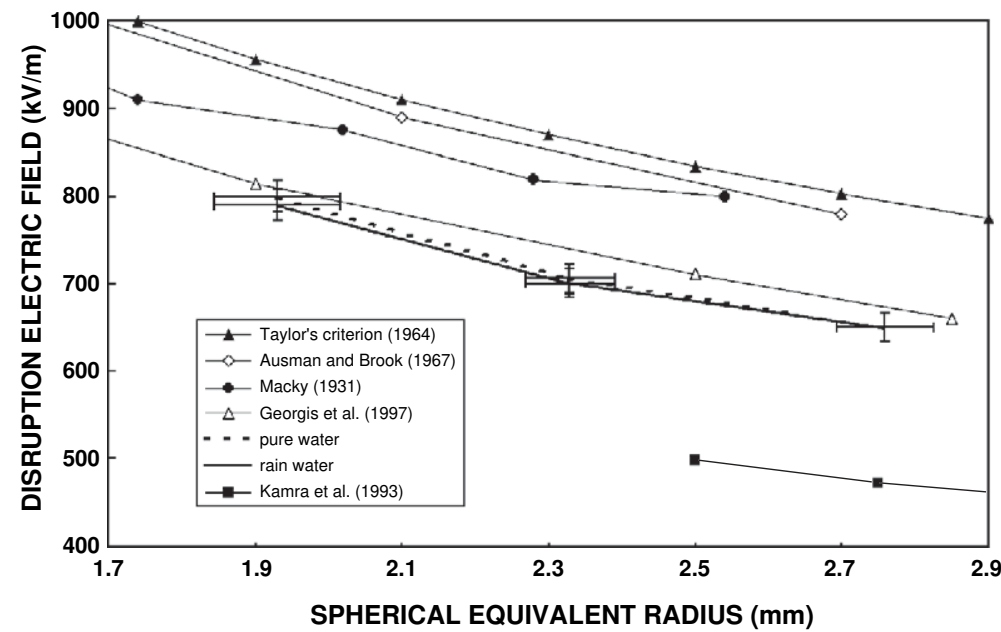

Fig. 2. Disruption electric field $(\mathrm{kV} / \mathrm{m})$ versus spherical equivalent radius $(\mathrm{mm})$ at atmospheric pressure. 
other hand the pressure differences between ground level and the altitudes at which water drops exist in thunderstorms are not so large. Nevertheless, they should be lower for charged raindrops (Coquillat et al., 2003) and in presence of turbulence (Kamra et al., 1993).

As far as the type of water is considered, this instability onset field appears quite unaffected by the water conductivity since the difference remains within the range of uncertainty of the measurements (see Fig. 2), which is weak as compared to the scatter of all available data in the literature. One could only suppose that the increase in conductivity could favour the reduction of the electric relaxation time (Latham and Myers, 1970) that would induce in turn a more rapid electric distortion. Consequently the onset field for rainwater should be slightly lower than that for pure water. This is what is observed but the difference is so tiny that we cannot conclude with present results.

\subsection{Discharge characteristics}

Displayed in Fig. 3, the discharge signals appear as series of sharp pulses of relatively high amplitude and low frequency for pure water, and of relatively low amplitude and high frequency for rainwater. The average peak current amplitude decreases from $42 \mathrm{~mA}$ to 21 $\mathrm{mA}$ with decreasing field (increasing size) for pure water whereas it increases from $7.4 \mathrm{~mA}$ to $13 \mathrm{~mA}$ with increasing field for rainwater. The average pulse rate remains quite unchanged (about $1.3 \mathrm{kHz}$ ) whatever the field is for pure water, but strongly decreases from $15 \mathrm{kHz}$ to $2.7 \mathrm{kHz}$ with decreasing field for rainwater. Each pulse lasts few hundreds of nanoseconds with a typical rising time of $0.1 \mu \mathrm{s}$. The total duration of these signals is about 7 to $10 \mathrm{~ms}$; the end of the signals presumably corresponds to the moment at which the drops leave the high field region. Both positive and negative signatures are very similar; no time lag has been detected even with a sampling rate of $5 \mathrm{~ns}$. Moreover, the average peak current amplitude displays the same features in both polarities except that the negative discharges exhibit lower intensities than positive discharges by an amount of about $10 \%$, i.e. $3 \mathrm{~mA}$ for pure water and $1 \mathrm{~mA}$ for rainwater (see Fig. 4).

By integrating the current signal, the average charge per pulse has been calculated in each case. The results are displayed in Fig. 4. The behaviour of this charge per pulse is similar to that of the average peak current amplitude, consequently the falling drops become negatively charged when leaving the high field region. However, no deviation of their trajectory has been observed presumably because their time of residence in the high field region is too short for the Coulomb force to influence their fall. When taking into account the whole discharge, the amount of residual charge on the observed raindrops ranges between $-4 \mathrm{nC}$ to $-1.6 \mathrm{nC}$ for increasing radius (decreasing field) in the case of pure water, and is about $-1 \mathrm{nC}$ for rainwater except for the larger size for which the charge is positive $(0.4 \mathrm{nC})$. One can point out that these last results for rainwater are probably not meaningful since the corresponding curves in Fig. 4 appear quite identical; i.e. the difference could arise from the measurement and calculation uncertainties.

\subsection{Interpretation of the discharge signals}

According to Latham and Myers (1970), raindrops falling in their disruption field are assumed to disintegrate and to loose charge and mass. Therefore one could wonder 

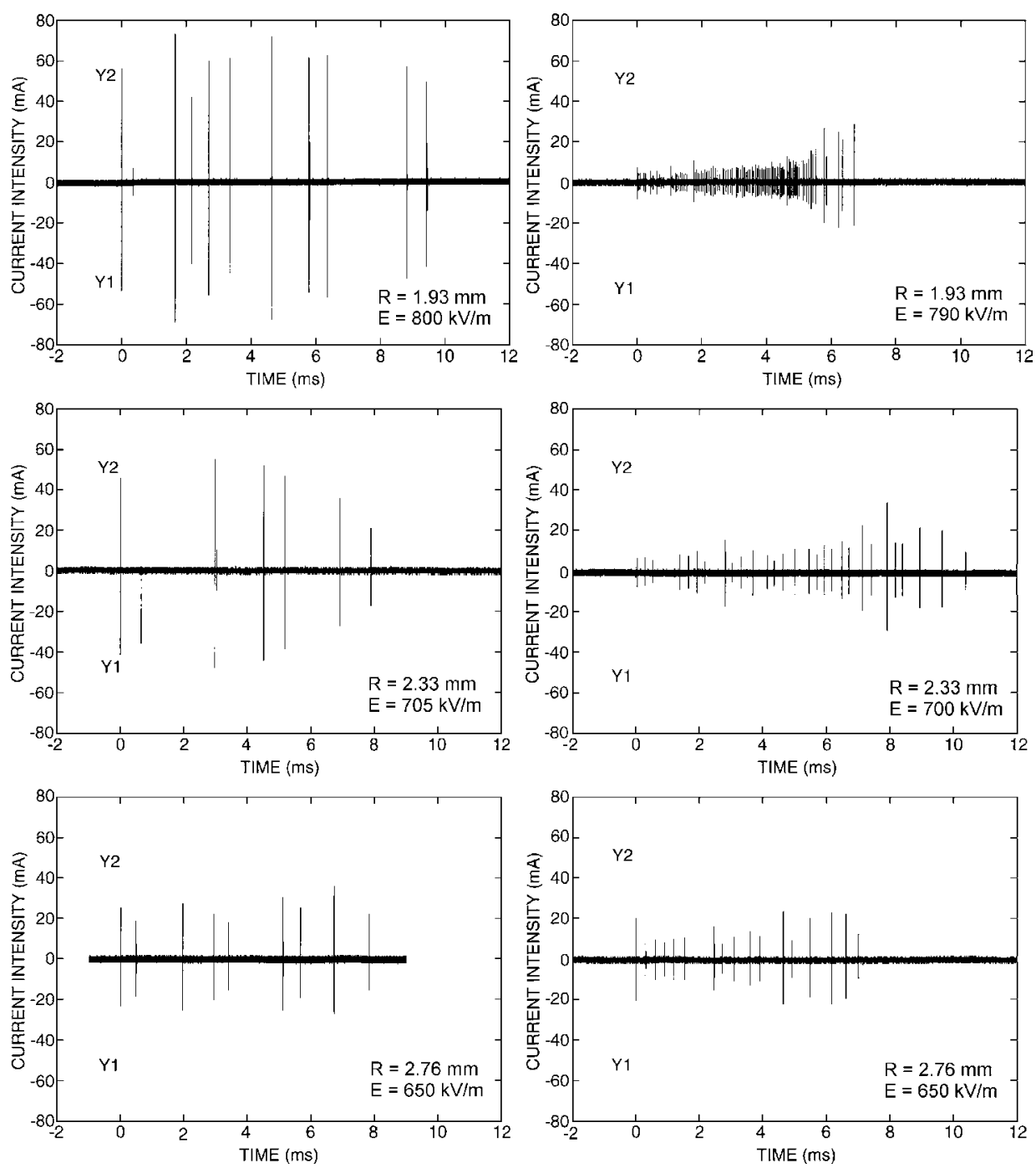

Fig. 3. Discharge signal from pure water drops (left) and rainwater drops (right) in their instability onset field.

whether small droplets ejected could affect the discharge signal. As seen in Fig. 3, the pulse frequencies highly depends on the water type. If these signals were due to water droplet ejection, the marked difference in the droplet ejection rate governed by the electromechanical behaviour of both types of water should unavoidably result in a marked difference in the disruption field intensity according to Dawson (1969). However, this one appears only slightly influenced by water nature (Fig. 2). As a matter of fact, the concentrations of the various salt elements of the rainwater never exceed about $10^{-5} \mathrm{~mol} /$ $\mathrm{kg}$ (see Table 1). Thus, the water surface tension that determines the disruption electric field is quite not affected by such low concentrations according to Pruppacher and Klett 


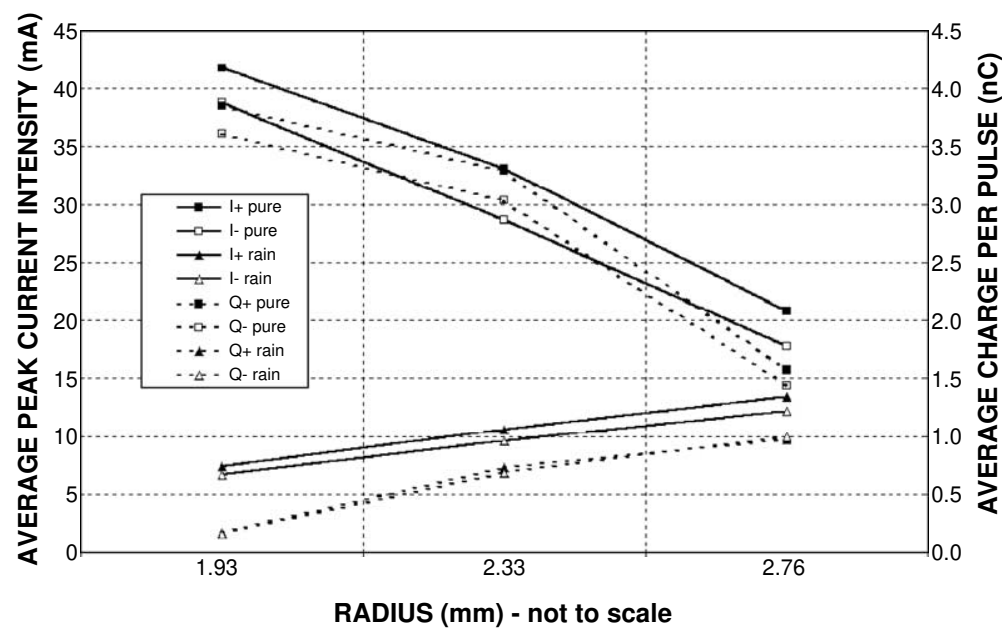

Fig. 4. Positive and negative average peak current $I$ (solid lines) and average charge per pulse $Q$ (dotted lines) in absolute value versus radius. Radius is not to scale.

(1997, p. 133). In this way, we doubt whether the detected current impulses could be influenced by charged droplets ejection. Furthermore, no water droplets were observed soon after each event on the chromed copper plates, though a specific care was taken to the cleaning of the plates because of possible inopportune violent flashing in high stress conditions. Maybe the drops were in phase of disruption but the residing time in the high field region would be, on one hand, too short for the drop to reach the onset of droplet ejection, but sufficient on the other hand for the corona emission to be triggered since the relaxation time for electrical conduction is several orders of magnitude shorter than that for fluid motion (Latham and Myers, 1970).

The discharge signals observed appear very similar and quite symmetrical for both polarities contrary to the observations of corona emission from ice hydrometeors by Griffiths and Latham (1974). In their experiment they observed each polarity separately and explored a large range of discharge regimes by enhancing the electric field intensity. For ice needles $5 \mathrm{~mm}$ long and $120 \mu \mathrm{m}$ in diameter at $-12{ }^{\circ} \mathrm{C}$ and $600 \mathrm{hPa}$, they found that the positive discharge commences with onset streamer pulses at a rate of about $1600 \mathrm{~Hz}$. For increasing fields, the pulses where larger and less regularly spaced and a DC component appeared. For negative polarity, the discharge signal exhibited Trichel pulses at a rate of about $1100 \mathrm{~Hz}$ that increased to about $4000 \mathrm{~Hz}$ with increasing field.

Because of hydrodynamic instability, pure corona discharge is impossible from water drops at atmospheric pressure (Dawson, 1969; Coquillat et al., 2003). Therefore the discharge signals observed here are the result of a strong deformation of the drop in process of disruption and the high conductivity of water - as compared to that of ice - could favour a strong correlation between discharges from both sides of the drops. Even if the pressure and the nature of the hydrometeors are different, the comparison with the results by Griffiths and Latham (1974) shows that the temporal characteristics of the discharges are of the same order, i.e., the discharge process is of the same nature. Nevertheless, it would have 
been more interesting for establishing better comparisons to observe pure corona emission from raindrops by controlling the pressure.

One could wonder why the positive and negative signals are so similar. Would the electrical circuit be responsible for that? Actually, it is of the same nature than that of Griffiths and Latham (1974) and the gap is even larger $(10 \mathrm{~cm}$ versus $6 \mathrm{~cm})$. One difference resides in the symmetry of the potentials that should not affect the triggering of discharge. Could the subsequent discharge process be affected? By virtue of electrical influence, the global circuit could be closed in such a way that the negative current corresponds to a replica of the positive current. But the pulsed nature of the discharge prevents from a direct connection of the drop to the plates that would change the potential configuration. Therefore we doubt whether the symmetry of the signal could be an artifact.

In this way, the symmetry of discharge signal suggests that the positive side, which is expected to have a lower corona threshold (Dawson, 1969), seems to control the whole discharge process. No doubt that when the discharge is triggered at the positive side, the negative side is influenced by the resulting charge displacement at the drop surface because of the short relaxation time for electrical conduction of water. But the fact that discharge signals are symmetrical for pure and rainwater in the present experiment shows that the difference in relaxation time is probably too tiny to reveal a difference in the temporal characteristics of the positive and negative discharges observed.

Given that the whole discharge appears to be controlled by the positive side, let us focus on the discharge process in positive polarity. According to the review by Griffiths and Latham (1974), the present mode of discharge is that of onset streamer pulses. The discharge is initiated in air near the distorted tip of the drop where the electric field is sufficiently high for accelerating free electrons that can cause the ionisation of gas molecules by collisions. This process releases new electrons that subsequently act in the same way. The whole process appears as an electron avalanche at the head of which electrons of high mobility rapidly progress in increasing fields until they are absorbed by the drop, leaving behind a space charge of low-mobility positive ions slowly progressing to the cathode in decreasing fields. In the mean time, $\mathrm{O}_{2}$ molecules excited by collision with electrons may return to their fundamental state by emitting a photon called photoelectron, which in turn can provoke the ionisation of other gas molecules close to the space charge (Griffiths and Latham, 1974) or close to the drop in a radial direction when the aborted streamer moves away (Loeb, 1965).

The process is that depicted in Loeb (1965, p. 140) with larger space charges and longer times. As pointed out by Griffiths and Latham (1974), the pulsed nature of the discharge is due to the positive space charge that inhibits further corona triggering until it is cleared by the action of the field. However the fall velocity of the drop acts in the same way for clearing the space charge. As a matter of fact, the drops falling approximately at $9 \mathrm{~m} / \mathrm{s}$ (Gunn and Kinzer, 1949) in present experiment cover from $0.6 \mathrm{~mm}$ to $6 \mathrm{~mm}$ between two pulses for repetition rates ranging between $15 \mathrm{kHz}$ and $1.5 \mathrm{kHz}$, respectively. These distances are not negligible with respect to the drop sizes. Therefore the space charge produced by the burst pulses moves faster away from the drop, consequently the discharge can be reactivated sooner than in the case of still drops. This reactivation may be triggered via the photons that are radially emitted from the previous aborted streamer. 
The influence of the water conductivity can be summarized in the following. First, a higher conductivity favours the existence of image charges on the drop that enhance the local field at the head of the avalanche. Second, the electrons at the head of the avalanche at the positive side of the drop are faster absorbed by the drop surface and are therefore less efficient in producing photons for secondary avalanches that could enhance the positive space charge of the aborted streamer. Consequently the discharge amplitude should be weaker. Given that the absorption of the negative charge at the head of the avalanche is faster, the local electric field near the surface of the drop should built up again more rapidly all the more as the positive space charge has moved away upward with respect to the drop because of its fall velocity. The pulsed discharge frequency should in turn increase with increasing conductivity, as it is observed in present experiment. Moreover, the charge transfer from one side of the drop to the other should be faster and the electrons would be more easily extracted from the negative side by the negative streamer, resulting in a closer interaction between the discharges on both sides of the drop.

\section{Discussion}

What consequences an increase in conductivity of polluted hydrometeors could have in thunderclouds? Jayaratne et al. (1983) found that increasing impurities concentration $\left(\mathrm{NaCl}, \mathrm{NH}_{4}\right.$ salts, etc.) into water droplets leads to enhance the charging in an experiment of non-inductive mechanism. Increasing salt concentrations leads also to increasing or decreasing the sign reversal temperature depending on the salt used. According to Avila et al. (1999), cloud droplets spectrum that could be altered by pollutants has an impact on graupel charge polarity with temperature.

As far as corona emission is considered, the present experiment shows that the onset field at low altitude (high pressure) of corona emission associated with the drop instability remains quite unaffected by the water conductivity. However it would be interesting to repeat the same experiment with much more polluted water for estimating its influence in a wider range of water conductivity. Not measured here, the pure corona onset field is not expected to be influenced by the water conductivity since this mechanism is triggered in the air. However, a higher conductivity could reinforce the presence of image charges on the drop surface, leading to an enhancement of the local field during the avalanche process. Could the corona onset field be affected and in what extent? Here again the control of the pressure in this kind of experiment would be welcome.

If we cannot state on the corona onset fields we can however assume that the discharge characteristics are affected by the water conductivity in the light of the present observations. In a same ambient electric field, highly polluted water should be able to emit pulses at higher rates than poorly polluted water. During the short time of interaction between two drops, a high pulse rate should favour the probability of connection between two pulses. The handicap of rather low peak current intensities could therefore be balanced by this interaction, leading to the streamer triggering. In this configuration, the transition from the onset streamer pulse to the streamer phase of discharge could therefore be favoured. The subsequent propagating streamer would presumably be more easily initiated from interacting polluted raindrops in such a way that stable streamer propagation (see 
Schroeder et al., 1999) could be sustained provided the ambient field is high enough (Griffiths and Phelps, 1976). As emphasized by Schroeder et al. (1999), if several streamers can merge to form a single and more vigorous streamer, the probability of leader formation would also be enhanced.

Recently, several studies focused on the lightning activity over cities (Westcott, 1995; Orville et al., 2001; Soriano and de Pablo, 2002; Steiger et al., 2002). All of them showed an enhancement of the lightning activity over urban areas compared with the neighbouring areas. As stated by Steiger and Orville (2003), three possible reasons can explain this urban lightning enhancement: the local topographic effects involving the sea breeze influence, the enhancement of the convection produced by the urban heat island, and the increase number of $\mathrm{CCN}$ that induces microphysical effects. By focusing on a small city far from the coast (Lake Charles, Louisiana) where see breeze and urban heat island effects can be disregarded, Steiger and Orville showed that pollution plays a key part in lightning enhancement. Their observations support the pollution hypothesis for lightning enhancement by Rosenfeld and Lensky (1998) discussed by Williams et al. (1999). According to this hypothesis, the increased number of CCN due to a dirty continental boundary layer induces the multiplication of small droplets that share the available liquid water in the storm updraft rendering the coalescence process less efficient due to the lack of mean droplet size. Subsequently, more cloud water can reach the mixed phase region in which droplets participate, among other processes, in the separation of electric charge. In this way, the cloud electrification would be increased and lightning activity would be enhanced too.

However, this explanation does not take account of the influence of CCN concentration on the Hallett-Mossop glaciation process. As described by Mossop and Hallett (1974) and by Mossop (1978), the secondary ice crystal production is sensitive to the drop size distribution. In particular, the presence of a high number of large drops is necessary. The release of $\mathrm{CCN}$ by anthropogenic activities tends to diminish the number of large drops and thus, to inhibit the Hallet-Mossop process. As this mechanism, which provides high ice crystal concentrations, is essential to cloud electrification (Hallett and Saunders, 1979), an increase in the number of $\mathrm{CCN}$ could produce a diminution in lightning activity.

It seems difficult to sort out the effects of pollution from other parameters on the lightning activity (Williams et al., 1999). However, one large-scale event of polluted storms cannot be solely explained by a local enhancement of the convection (Murray et al., 2000). In May 1998, thunderstorms in the U.S. southern plains were polluted by smoke from fires from seasonal biomass burning in Central America. Murray et al. (2000) compared the cloud-to-ground lightning characteristics to that of May 1995-1997 and 1999. May 1998 exhibits a marked increase in the percentage and in the median peak current of positive ground flashes (more than 50\% and $20 \mathrm{kA}$, respectively), and an invariance of CG+ multiplicity in Texas. Smith et al. (2003), who have realized a numerical analysis of this fire event, found that lightning characteristics are apparently not affected neither by $\mathrm{CCN}$ concentration nor by the type of aerosol (only two different species were simulated). They reported that during the month of May 1998, the atmosphere of the southern Great Plains was abnormally dry so that the lightning anomalies could originate from the induced presence of strong lower positive charge centres responsible for high $+\mathrm{CG}$ flash rate (see Smith et al., 2003). However, the criterion 
used in their model for lightning initialization is probably and unavoidably too simplified (200 kV/m threshold electric field) to account for the possible influence of aerosols on the various phases of lightning discharge process, like the influence - via the conductivity - on the corona discharges observed in present experiment.

As a matter of fact, one can wonder whether the branching process could be influenced by the aerosols via the polluted water conductivity. According to Mazur (2002), an upward negative leader connecting to the positive cloud charge in the case of $\mathrm{CG}+$ is much more branched than an upward positive leader connecting to the negative cloud charge in the case of $\mathrm{CG}-$. Each branch of the leader being an additional current source that feeds the return stroke channel, the higher the branching process is efficient, the higher the first return stroke current is intense since only the first return stroke follows the whole branching path. This mostly happens in the case of $\mathrm{CG}^{+}$. Assuming that a high degree of branching necessarily corresponds to a strong interaction between the leader and the microphysical population, one can expect that upward negative leaders involved in the triggering of $\mathrm{CG}+$ would be more sensitive to the cloud microphysical population than would positive leaders of $\mathrm{CG}-$. The question is: does the water conductivity affect this interaction?

Relatively few studies related to the interaction between microphysics and electric discharge are available in the literature mainly because of experimental constraints that are difficult to overcome. Williams et al. (1985) analyzed the interaction between the electric discharge and the space charge in a solid dielectric material. They found that the discharge propagates preferentially in regions of high charge density and avoid regions of low charge density, but the possible part played by the equivalent conductivity of cloud drops is impossible to infer. Recently Temnikov et al. (2003) performed a interesting laboratory experiment in which they observed the discharge characteristics between a charged cloud and a grounded electrode. However, only one type of water was used. Sugimoto et al. (1999) previously made the same kind of experiment but at smaller scale. Tardiveau and Marode (2003) have shown that dielectric droplets of micrometric size are likely to modify the development of filamentary discharges. The presence of droplets induces a guiding effect and reduces the critical potential for streamer-to-arc transition. According to Tardiveau and Marode, the extraction of electrons from the droplets surface that further participate in the discharge propagation is favoured by a reduction of the ionization energy that is function of the increasing relative permittivity, hence of the increasing conductivity.

As we do not know much about the influence of water drops conductivity on streamer development one can only speculate on the further consequences of an increasing conductivity of water droplets on the branching of leaders. If one emphasizes that a propagating streamer is more easily initiated from polluted drops according to Tardiveau and Marode (2003), the threshold for sustained discharge propagation would be reduced and discharges would tend to branch more extensively. For example, since the microphysical population that interacts with the branching process is submitted to a high electric field due to the upward negative leader, the higher the field the higher the probability of connection of pulses from interacting polluted raindrops (see Fig. 5). Subsequently, the branching should be more developed in a population of polluted hydrometeors. This could favour the development of negative leaders that trigger $\mathrm{CG}^{+}$, resulting in an increase in the percentage of $\mathrm{CG}^{+}$. It should also enhance the peak current intensity of the first return stroke. On the contrary, the multiplicity of the $\mathrm{CG}^{+}$should not 


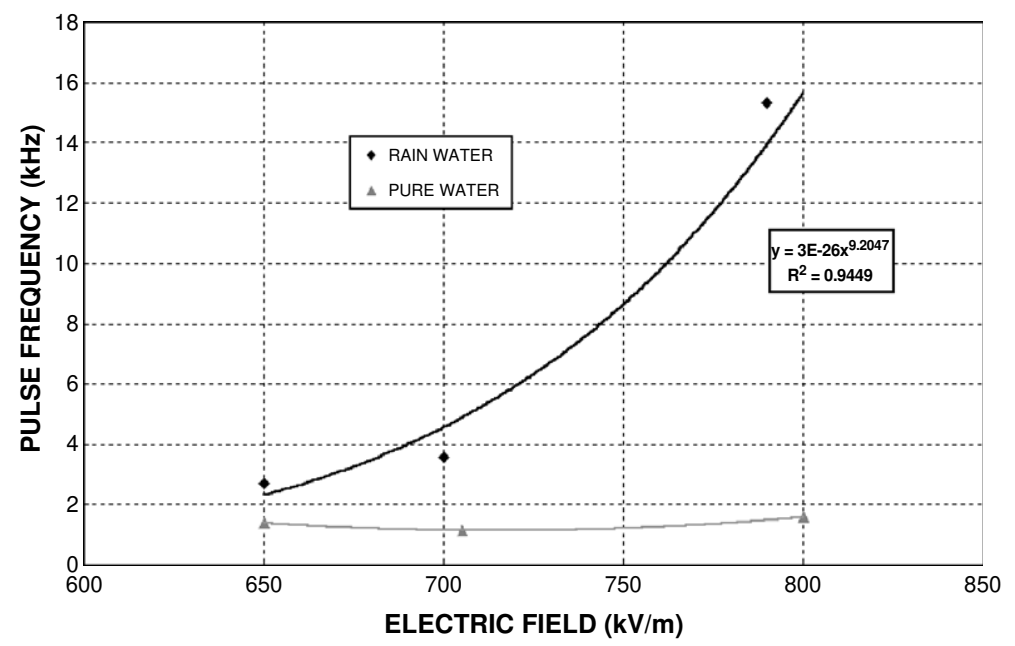

Fig. 5. Pulse frequency $(\mathrm{kHz})$ versus electric field $(\mathrm{kV} / \mathrm{m})$ for various sizes of rain and pure water drops.

be affected since the subsequent dart leaders and return strokes do not follow the whole channel ramifications and thus their interaction with the polluted microphysical population is limited. However, this kind of scenario remains speculative and further studies are required to identify the actual processes involved in this interaction.

Furthermore, if present hypothesis on the water conductivity influence seems to fit with the observations by Murray et al. (2000), one must keep in mind that pollution properties are numerous and depend on the nature of contaminants and aerosols. Many atmospheric pollutants play the role of $\mathrm{CCN}$ and thus, widely modify cloud microphysics. To sum up, as soon as we consider pollution effect, numerous parameters, with numerous influences, are involved and it seems difficult to conclude on the whole lightning activity.

\section{Conclusion}

The present experimental results clearly show that water conductivity is a parameter that controls the characteristics of the micro-discharges triggered from raindrops in the onset streamer pulse mode: the higher the conductivity, the higher the pulse frequency and the lower the peak current intensity. We have analysed the influence that a high water conductivity due to the atmospheric pollution could have on various electrical mechanisms in thunderclouds. If the presence of pollutants are known to affect the non inductive charging or the temperature of sign reversal (Jayaratne et al., 1983), the part played by pollution on the thundercloud electrification via the influence of $\mathrm{CCN}$ on microphysics is still under debate. On one hand observations by Westcott (1995), Steiger and Orville (2003), and others, tend to confirm the hypothesis by Rosenfeld and Lensky (1998) and Williams et al. (1999) according to which the increased number of CCN leads to a share of the available water between numerous smaller droplets that prevents from coalescence and allows water droplets to reach the mixed phase region and intensify the electrification 
process. On the other hand, the lack of large drops resulting from the increased number of $\mathrm{CCN}$ due to pollution inhibits the Hallett-Mossop process that provides high ice crystal concentrations, which are essential to cloud electrification according to Hallett and Saunders (1979). Lightning activity that depends on cloud electrification could therefore be reduced or increased according to both points of view. As a matter of fact, this basic conclusion does not consider the various processes that are involved in lightning triggering and that could be affected by pollution whatever the degree of electrification is. Specific studies are therefore required to clearly identify the influence of pollution on each step of the lightning discharge development.

As far as the corona onset field is considered, present experiment cannot provide any valuable conclusion since the measurements have been made only at atmospheric pressure when it is known that corona emission is clearly favoured by a decrease in pressure (Dawson, 1969). A new experiment with controlled pressure would be required for better analysing the water conductivity influence on the various modes of discharge from water drops at low pressure (for increasing fields above the onset). It would also be profitable to enlarge the water conductivity range in order to better account for the discharge mechanisms associated with high polluted events. At last, the study of interacting polluted drops at low pressure could bring valuable new information on the streamer triggering conditions.

\section{Acknowledgements}

We thank Monique Delapart for providing the water analysis, Xavier Silvani for his help in the experimental apparatus design and setting up, and all the members of the Centre de Recherches Atmosphériques de Lannemezan for their technical support. We are grateful to the reviewers who helped us to greatly improve the manuscript.

\section{References}

Ausman, E.L., Brook, M., 1967. Distortion and disintegration of water drops in strong electric fields. J. Geophys. Res. 72, 6131-6135.

Avila, E.E., Pereyra, R.G., Varela, G.G.A., Caranti, G.M., 1999. The effect of the cloud-droplet spectrum on electrical-charge transfer during individual ice-ice collisions. Q. J. R. Meteorol. Soc. 125, 1669-1679.

Brazier-Smith, P.R., Latham, J., 1969. Numerical computations of the dynamics of the disintegration of a drop situated in an electric field. Proc. R. Soc., Ser. A 312, 277-289.

Coquillat, S., Combal, B., Chauzy, S., 2003. Corona emission from raindrops in strong electric fields as a possible discharge initiation: comparison between horizontal and vertical field configurations. J. Geophys. Res. 108 (D7), 4205.

Crabb, J.A., Latham, J., 1974. Corona from colliding drops as a possible mechanism for the triggering of lightning. Q. J. R. Meteorol. Soc. 100, 191-202.

Dawson, G.A., 1969. Pressure dependence of water drops corona onset and its atmospheric importance. J. Geophys. Res. 74, 6859-6868.

English, W.N., 1948. Corona from a water drop. Phys. Rev. 74, 179-189.

Georgis, J.F., Chauzy, S., Coquillat, S., 1995. Computed conditions of corona emission from two interacting raindrops. Q. J. R. Meteorol. Soc. 121, 1853-1866. 
Georgis, J.F., Coquillat, S., Chauzy, S., 1997. Onset of instability in precipitating water drops submitted to horizontal electric fields. J. Geophys. Res. 102, 16793-16798.

Griffiths, R.F., Latham, J., 1972. The emission of corona from falling drops. J. Meteorol. Soc. Jpn. 50 (5), 416-422.

Griffiths, R.F., Latham, J., 1974. Electrical corona from ice hydrometeors. Q. J. R. Meteorol. Soc. 100, 163 - 180.

Griffiths, R.F., Phelps, C.T., 1976. The effects of air pressure and water vapour content on the propagation of positive corona streamers, and their implications to lightning initiation. Q. J. R. Meteorol. Soc. 102, $419-426$.

Gunn, R., Kinzer, G.D., 1949. The terminal velocity of fall for water droplets in stagnant air. J. Meteorol. 6, $243-248$.

Hallett, J., Saunders, C.P.R., 1979. Charge separation associated with secondary ice crystal production. J. Atmos. Sci. 36, 2230-2235.

Jayaratne, E.R., Saunders, C.P.R., Hallett, J., 1983. Laboratory studies of the charging of soft hail during ice crystal interactions. Q. J. R. Meteorol. Soc. 109, 609-630.

Kamra, A.K., Ahire, D.V., 1989. Wind-tunnel studies of the shape of charged and uncharged water drops in the absence or presence of an electric field. Atmos. Res. 23, 117-134.

Kamra, A.K., Bhalwankar, R.V., Sathe, A.B., 1993. The onset of disintegration and corona in water drops falling at terminal velocity in horizontal electric fields. J. Geophys. Res. 98, 12901-12912.

Latham, J., Myers, V., 1970. Loss of charge and mass from raindrops falling in intense electric fields. J. Geophys. Res. 75, 515-520.

Loeb, L., 1965. Electrical Coronas. Univ. Calif. Press, Berkeley. 694 pp.

Lyons, W., Nelson, T., Williams, E., Cramer, J., Turner, T., 1998. Enhanced positive cloud-to-ground lightning in thunderstorms ingesting smoke from fires. Science $282,77-80$.

MacGorman, D.R., Rust, W.D., 1998. The Electrical Nature of Storms. Oxford University Press, New York, USA. 422 pp.

Macky, W.A., 1931. Some investigations on the deformation and breaking of water drops in strong electric fields. Proc. R. Soc. Lond., Ser. A 133, 565-587.

Mazur, V., 2002. Physical processes during development of lightning flashes. C. R. Physique 3, 1393-1409.

Mossop, S.C., 1978. The influence of drop size distribution on the production of secondary ice particles during graupel growth. Q. J. R. Meteorol. Soc. 104, 323-330.

Mossop, S.C., Hallett, J., 1974. Ice crystal concentration in cumulus clouds: influence of the drop spectrum. Science $186,632-634$

Murray, N.D., Orville, R.E., Huffines, G.R., 2000. Effect of pollution from Central American fires on cloud-toground lightning in May 1998. Geophys. Res. Lett. 27, 2249-2252.

Orville, R.E., Huffines, G., Nielsen-Gammon, J., Zhang, R., Ely, B., Steiger, S., Phillips, S., Allen, S., Read, W., 2001. Enhancement of cloud-to-ground lightning over Houston, Texas. Geophys. Res. Lett. 28, 2597-2600.

Pruppacher, H.R., Klett, J.D., 1997. Microphysics of Clouds and Precipitation, 2nd edition. Kluwer Academic Publishers. 954 pp.

Richards, C.N., Dawson, G.A., 1971. The hydrodynamic instability of water drops falling at terminal velocity in vertical electric fields. J. Geophys. Res. 76, 3445-3455.

Rosenfeld, D., Lensky, I.M., 1998. Satellite-based insights into precipitation formation processes in continental and maritime convective clouds. Mon. Weather Rev. 79, 2457-2476.

Sanusi, A., Wortham, H., Millet, M., Mirabel, P., 1996. Chemical composition of rainwater in eastern France. Atmos. Environ. 30, 59-71.

Schroeder, V., Baker, M.B., Latham, J., 1999. A model study of corona emission from hydrometeors. Q. J. R. Meteorol. Soc. 125, 1681-1693.

Smith, J.A., Baker, M.B., Weinman, J.A., 2003. Do forest fires affect lightning? Q. J. R. Meteorol. Soc. 129, 2651-2670.

Soriano, L.R., de Pablo, F., 2002. Effect of small urban areas in central Spain on the enhancement of cloud-toground lightning activity. Atmos. Environ. 36, 2809-2816.

Steiger, S.M., Orville, R.E., 2003. Cloud-to-ground lightning enhancement over Southern Louisiana. Geophys. Res. Lett. 30 (19), 1975. 
Steiger, S.M., Orville, R.E., Huffines, G., 2002. Cloud-to-ground lightning characteristics over Houston, Texas: 1989-2000. J. Geophys. Res. 107 (ACL 2), 1-13.

Sugimoto, T., Tanaka, S., Higashiyama, Y., Asano, K., 1999. Formation of a charged droplets cloud and corona discharge between the cloud and a grounded electrode. IEEE Trans. Ind. Appl. 35, 225-230.

Tardiveau, P., Marode, E., 2003. Point-to-plane discharge dynamics in the presence of dielectric droplets. J. Phys. D: Appl. Phys. 36, 1204-1211.

Temnikov, A.G., Vereshchagin, I.P., Orlov, A.V., Sokolova, M.V., 2003. Investigation of the main stage of a discharge between an artificially charged water aerosol cloud and a grounded electrode. Proceedings of the 12th Int. Conf. Atmospheric Electricity, 9-13 June, Versailles, France, 549-552.

Vázquez, A., Costoya, M., Peña, R.M., García, S., Herrero, C., 2003. A rainwater quality monitoring network: a preliminary study of the composition of rainwater in Galicia (NW Spain). Chemosphere 51, 375-386.

Wang, P.K., Pruppacher, H.R., 1977. Acceleration to terminal velocity of cloud and raindrops. J. Appl. Meteorol. $16,275-280$.

Westcott, N.E., 1995. Summertime cloud-to-ground lightning activity around major midwestern urban areas. J. Appl. Meteorol. 34, 1633-1642.

Williams, E., Cooke, C.M., Wright, K.A., 1985. Electrical discharge propagation in and around space charge clouds. J. Geophys. Res. 90, 6059-6070.

Williams, E., Rosenfeld, D., Madden, N., Labrada, C., Gerlach, J., Atkinson, L., 1999. The role of boundary layer aerosol in the vertical development of precipitation and electrification: another look at the contrast between lightning over land and over ocean. Proceedings of the 11th International Conf. Atmospheric Electricity, Guntersville, AL, 754-757.

Windmar, D., 1994. Water drop initiated discharges in air, Acta Universitatis Upsaliensis, Uppsala Dissertations from the Faculty of Science and Technology 1. 